\title{
Two-weeks of elbow immobilization affects torque production but does not change muscle activation
}

\section{Duas semanas de imobilização do cotovelo afetam a produção de torque, porém não alteram a ativação elétrica}

Ana P. B. Karolczak' ',2,3, Fernando Diefenthaeler', Jeam M. Geremia', Marco A. Vaz'

\begin{abstract}
Background: Limb immobilization has been extensively used during the recovery process of musculoskeletal injuries despite the fact that this technique causes functional deficits in the skeletal muscle. There is evidence showing strength reduction due to muscle hypotrophy and an increase in the percentage of fast-twitch fibers, however it is still unclear how the injuries and the immobilization contribute to these changes. Objective: To verify the influence of elbow joint immobilization on the torque-angle relationship and on electrical activation of the elbow flexor and extensor muscles in healthy subjects. Methods: Eighteen male subjects (22 to 42 years) were assigned to either a control group $(n=11)$ or to an immobilization group $(n=7)$. All subjects performed the same tests twice with a 14-day interval period. The immobilization group had the non-dominant elbow joint immobilized with a cast at a joint angle of $90^{\circ}$ during 14 days. Maximal isometric torques were obtained with the elbow joint positioned at $150^{\circ}, 120^{\circ}, 90^{\circ}$ and $60^{\circ}$. Results: There was a $16 \%$ reduction in maximal torque after immobilization that cannot be explained by changes in arm girth or by reduction in the electrical activation of the muscles. Conclusions: Fourteen days of immobilization produced a reduction in maximal elbow isometric torque but did not change muscle activation in healthy subjects. This reduction in maximal torque production seems to be related to muscle hypotrophy and is probably less pronounced when compared to that from immobilization after musculoskeletal injuries.
\end{abstract}

Key words: immobilization; electromyography; torque; elbow joint.

\section{Resumo}

Contextualização: A imobilização tem sido amplamente utilizada para recuperação de lesões musculoesqueléticas, entretanto essa técnica causa déficits funcionais no sistema musculoesquelético. Existe uma série de evidências demonstrando redução da força devido à hipotrofia muscular e um incremento do percentual de fibras rápidas, embora as contribuições relativas à lesão ou à imobilização ainda não estejam totalmente esclarecidas. Objetivo: Verificar a influência da imobilização do cotovelo na relação torqueângulo e na ativação elétrica dos flexores e extensores em sujeitos saudáveis. Métodos: Dezoito sujeitos do sexo masculino (22-42 anos) foram divididos em um grupo controle $(n=11)$ e em um grupo imobilizado $(n=7)$. Todos os sujeitos realizaram os mesmos testes duas vezes, com intervalo de 14 dias. O grupo imobilizado teve seu cotovelo não-dominante imobilizado com uma tala gessada no ângulo de $90^{\circ}$ durante 14 dias. O torque máximo isométrico foi obtido nos ângulos de $150^{\circ}, 120^{\circ}, 90^{\circ}$ e $60^{\circ}$. Resultados: Houve redução de $16 \%$ no torque máximo após a imobilização, o que não pode ser explicado por alterações na medida de perimetria ou na ativação elétrica muscular. Conclusões: A imobilização de 14 dias produziu uma redução no torque máximo isométrico do cotovelo, porém não alterou a ativação elétrica em sujeitos saudáveis. Essa redução parece estar relacionada à hipotrofia muscular e, provavelmente, menos intensa quando comparada à imobilização após lesões musculoesqueléticas.

Palavras-chave: imobilização; eletromiografia; torque; cotovelo.

Received: 26/09/2008 - Revised: 15/01/2009 - Accepted: 31/03/2009 


\section{Introduction $: \therefore$.}

Limb immobilization is widely used in the recovery of musculoskeletal injury. The effects of immobilization on muscle function have been studied in the past ${ }^{1,2}$; however, these effects are not fully understood in in vivo models. Knowledge of these effects is important for physical therapy, as reduced use of the musculoskeletal system partially impairs activities of daily living (ADLs). Furthermore, the amount of time necessary to recover from immobilization is greater than that of immobilization itself ${ }^{3}$.

The skeletal muscle is a dynamic tissue and it is highly adaptable to its functional demands ${ }^{4}$. Neuromuscular activity results from the combination of electrical activity delivered by the central nervous system and the external load applied to the muscle. These two factors determine the morphological, biochemical and functional properties of a muscle ${ }^{5}$. Reduction in load due to reduced use can change these properties. Several models have been proposed to study skeletal muscle adaptation. Models of increased use (such as training ${ }^{6}$ and electrical stimulation ${ }^{7}$ ) and of decreased use (such as immobilization ${ }^{8}$, spinal cord transection, hindlimb or lower extremity suspension ${ }^{9}$, space simulation ${ }^{10}$ and bed rest ${ }^{11}$ ) have been described. The main findings of reduced use models are a reduction in electrical activation ${ }^{12}$ and in the percentage of slow-twitch fibers, in the cross-sectional fiber area, and in muscle strength ${ }^{13}$.

Antigravity muscles have a high percentage of slow-twitch fibers and are more prone to hypotrophy due to immobilization than fast-twitch muscles ${ }^{14}$. Antigravity muscles seem to undergo a higher reduction in use during immobilization, because of the drastic reduction in ADLs. This preferential fiber hypotrophy affects the contractile properties of a muscle. Peak twitch torque, fatigue resistance, strength-length and strengthvelocity relationships change after a period of immobilization. However, results from different studies show controversies ${ }^{15,16}$, which might be due to fiber type heterogeneity among the studied muscles ${ }^{17}$. Addition or removal of sarcomeres in series has been shown to depend on the joint configuration (or the length) at which the muscle was immobilized ${ }^{18}$, i.e. the effects of immobilization depend on length.

Despite the fact that immobilization dates back more than two thousand years, knowledge of its effects in humans is poorly described. Most studies used animal models (e.g. $17,19)$, and the few human studies found in the literature are related to lower limb immobilization after an injury ${ }^{19,20}$. In order to understand purely the effects of limb immobilization on muscle properties it is necessary to differentiate the effects of injury from the effects of immobilization. Also, it is important to determine whether immobilization affects lower and upper limb muscles in the same way, as they have different uses during ADLs and are therefore subjected to different loads.

The purpose of this study was to compare maximal torque and electromyographic (EMG) signals of elbow flexors and extensors of healthy subjects before and after a two-week immobilization period. We hypothesized that absolute torque and EMG would decrease after 14 days of immobilization on the immobilized side in the immobilized group. This decrease would be greater in the flexor muscles compared to the extensor muscles due to the fact that the first muscle group is used more often in ADLs.

\section{Methods : :}

Eighteen healthy male subjects were intentionally selected to participate in the study. They were assigned to either a control ( $\mathrm{n}=11$, age $=25.55 \pm 4.59$ years $)$ or an immobilization group $(\mathrm{n}=7$, age $=30.43 \pm 7.66$ years $)$. All subjects signed a consent form to participate in the study, which was approved by the Ethics Committee of Universidade Federal do Rio Grande do Sul (protocol no 2005502).

\section{Immobilization}

The non-dominant upper limb of the subjects in the immobilization group was immobilized by means of a plaster cast, from the superior region of the biceps brachii to the wrist region, for a period of 14 days at an orthopedics clinic. The elbow joint was immobilized at an angle of $90^{\circ}\left(180^{\circ}=\right.$ full extension $)$, with the forearm at neutral position, whereas the shoulder and the radiocarpal joints and the fingers remained free in order to minimize the effects of immobilization on ADLs. The dominant upper limb served as a contralateral control, in addition to the control group.

\section{Anthropometrical measurements}

Four perimeter measurements were taken from each upper limb using a metric scale. Measurements were taken proximally with $5 \mathrm{~cm}$ increments starting at the olecranon. Measurements were repeated in the experimental group immediately after removal of the plaster cast.

\section{Torque}

Elbow flexor and extensor torques were obtained with a Cybex NORM isokinetic dynamometer (Lumex \& Co., Ronkonkoma, NY, USA). Subjects were seated on the 
dynamometer chair, with the shoulder at an angle of $45^{\circ}$ of abduction. The radio-ulnar and wrist joints were maintained at a neutral position. The apparent elbow joint rotation axis was aligned with the dynamometer rotation axis.

\section{Electromyographic signals}

EMG signals from the short and long heads of the biceps and triceps brachii and from the brachioradialis muscles were obtained with an eight-channel EMG system (AMT-8, Bortec Biomedical Ltd., Canada). Bipolar surface electrodes (Kendall, MEDITRACE- 100; Ag/AgCl; 2 mm diameter, $2.2 \mathrm{~cm}$ inter-electrode distance) were positioned at the distal third of the muscle belly in the assumed direction of the muscle fibers. A reference electrode was positioned on the skin over the olecranon. EMG standard procedures were observed for skin preparation prior to electrode placement ${ }^{21}$. In the immobilization group, a waterproof skin marker was used to mark the position of the EMG electrodes and ensure that the signals would come from the same place in the pre- and post-immobilization tests. In the control group, the marks left from hair removal during skin preparation were used for electrode placement due to the fact that the marks from the waterproof skin markers fade away with daily cleansing. There is evidence showing the reliability of the signals, as both root mean square (RMS) and median frequency values of isometric contractions of the quadriceps muscle were shown to be similar from EMG signals collected on different days ${ }^{22}$. All data were collected with a sampling frequency of $2000 \mathrm{~Hz}$ per channel (Windaq; Dataq Instruments, Akron, OH, USA; DI $720-16$ bits \pm 10 Volts).

\section{Evaluation protocol}

After the anthropometrical measurements, subjects warmed up by actively flexing and extending the elbow joint throughout the total range of motion for a period of five minutes. Next, EMG electrodes were positioned and subjects were properly seated on the dynamometer chair. Subjects were asked to perform three five-second maximal voluntary isometric contractions (MVICs) with the elbow at an angle of $90^{\circ}$. Subjects performed one MVIC with the elbow at $180^{\circ}$ (full extension), $150^{\circ}, 120^{\circ}, 90^{\circ}$ and $60^{\circ}$. A two-minute interval was observed between contractions in order to avoid fatigue ${ }^{23}$. The order of execution was randomized, and the first evaluated angle was re-tested at the end of the protocol to evaluate possible effects of fatigue. Subjects always performed flexor MVICs before extensor MVICs at each joint angle. All subjects repeated the same test in the contralateral side.

After the end of the initial test subjects in the immobilization group were taken to the orthopedics clinic for immobilization, which was removed two weeks later. Immediately (within two hours) after removal of the casts, subjects were taken to the laboratory for the post-immobilization tests. Control group subjects were re-tested 14 days after the first test.

\section{Data analysis}

\section{Torque}

Torque values obtained at each joint angle were expressed as a function of elbow angle both for elbow flexors and extensors in both groups. Relative values were calculated by normalizing the torque values obtained at the different elbow angles by the torque value obtained at the initial (highest) MVIC obtained at $90^{\circ}$. This normalization procedure was used in order to assess possible effects of immobilization on torque at different muscle lengths given that it has been shown that immobilization is length-dependent ${ }^{18}$.

\section{Electromyographic signals}

Torque signal was synchronized with the EMG signals. Onesecond segments were extracted from the middle (plateau) of the five-second MVICs ${ }^{23}$. EMG signals were scaled down to zero, the gain was removed and a band-pass $(10-500 \mathrm{~Hz})$ butterworth filter was applied to the signals. A fast fourier transformation (FFT) algorithm was applied to the signal to detect any noise, which was removed with a notch filter when necessary. Signals were extracted as previously explained, and RMS values were calculated and expressed as a function of elbow angle. Relative values were obtained by normalizing all RMS values to the RMS value obtained in the initial MVIC of each test. The software MATLAB ${ }^{\circledR}$ version 7.0 (MathWorks Inc., USA) was used for signal analysis.

\section{Statistical analysis}

Values were expressed as mean and standard deviation of the mean. Shapiro-Wilk (normality) and Levene (homogeneity) tests were chosen based on the sample size. An unpaired $t$ test was used to compare the anthropometrical data between the two groups. A three-way analysis of variance for repeated measures was used to compare absolute torque and RMS values, and relative torque and RMS values with respect to group (control vs. immobilization), angle and test (pre- and post-immobilization). When interaction was observed, a one-way analysis of variance for repeated measures was adopted. A Bonferroni post-hoc test was used to determine the differences. The paired $t$ test was used for comparison between sides and between the first and last contraction of the protocol. A significance level of 0.05 was adopted for all tests. All analyses were performed using the software SPSS (version 10.0). 


\section{Results : :}

\section{Anthropometrical data}

The mean body mass was $86.83 \pm 6.37 \mathrm{Kg}$ and $78.92 \pm 3.54 \mathrm{Kg}$, and mean height was $177 \pm 10.97 \mathrm{~cm}$ and $179.50 \pm 6.24 \mathrm{~cm}$, in the control and immobilized groups, respectively. No differences were observed in the anthropometrical data (body mass, height and arm perimeter) between groups before treatment and between testing days within groups.

\section{Torque data}

No fatigue effects were observed, as there was no difference between the torque values of the first and last MVICs of the protocol $(p=0.19)$ for both groups. Also, the MVIC intra-class coefficient of both flexors and extensors was equal to or higher than 0.90 (Table 1). Absolute peak torques were obtained at the joint angle of $90^{\circ}$ for all subjects in both muscle groups. The elbow torque as a function of elbow angle increased with increasing muscle length from $60^{\circ}$ to $90^{\circ}$ in the flexors and decreased with further length increases (from $90^{\circ}$ to $180^{\circ}$ ). For the extensors, absolute torque increased with increasing muscle length from $180^{\circ}$ to $90^{\circ}$, and decreased from $90^{\circ}$ to $60^{\circ}$ (Table 2 ).

No differences were observed in the absolute torque values of the elbow flexors and extensors of the control group between tests 1 and 2 (Table 2), except for the increase in torque at $60^{\circ}$ on the right side $(p=0.009)$ and the decrease at $180^{\circ}$ on the left side $(\mathrm{p}=0.02)$. Absolute flexor torque decreased for all joint angles after immobilization $\left(180^{\circ}=18 \%\right.$, $\mathrm{p}=0.029 ; 150^{\circ}=24 \%, \mathrm{p}=0.023 ; 120^{\circ}=20 \%, \mathrm{p}=0.012 ; 90=15 \%$, $\left.\mathrm{p}=0.014 ; 60^{\circ}=17 \%, \mathrm{p}=0,042\right)$. The comparison between sides revealed a torque decrease at the joint angles of $120^{\circ}(\mathrm{p}=0.09)$, $90^{\circ}(\mathrm{p}=0.018)$ and $60^{\circ}(\mathrm{p}=0.03)$.

Inter-group comparison revealed similar absolute flexor torque values on both sides (dominant and non-dominant) for all elbow angles in the first test ( 1 and pre-immobilization), except for $60^{\circ}$, which was higher in the immobilization group compared to the control group $(p=0.045)$. In the second test, the non-dominant side showed higher absolute torque values at the elbow angle of $120^{\circ}(p=0.039)$ in the control group.

No difference was observed between tests for the extensors in the dominant and non-dominant sides in control group. Absolute extensor torque decreased at all joint

Table 1. Intra-class correlation coefficient and the difference between the MVIC measurements of flexor and extensor muscles.

\begin{tabular}{lccccccc} 
Muscles & $\begin{array}{c}\text { Measure 1 } \\
\text { Mean } \pm \text { SD }\end{array}$ & $\begin{array}{c}\text { Measure 2 } \\
\text { Mean } \pm \text { SD }\end{array}$ & Difference & SEM Difference & $\begin{array}{c}95 \% \mathrm{Cl} \\
\text { Difference }\end{array}$ & ICC & $95 \%$ Cl ICC \\
\hline FD & $54.0 \pm 20.5$ & $53.6 \pm 21.7$ & 0.4 & 1.02 & -1.9 to 2.6 & 0.994 & 0.976 to 0.998 \\
\hline FND & $59.6 \pm 25.3$ & $59.0 \pm 23.9$ & 0.6 & 1.36 & -2.5 to 3.6 & 0.992 & 0.969 to 0.998 \\
\hline ED & $54.6 \pm 19.0$ & $53.4 \pm 17.8$ & 1.2 & 1.77 & -2.7 to 5.2 & 0.974 & 0.903 to 0.993 \\
\hline END & $57.4 \pm 22.2$ & $58.1 \pm 20.8$ & 0.7 & 1.94 & -5.1 to 3.6 & 0.977 & 0.915 to 0.994 \\
\hline
\end{tabular}

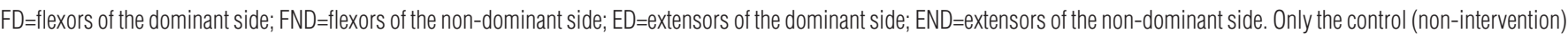
group was considered for this analysis. The first and last torque measurements obtained during the protocol were used to evaluate possible fatigue effects.

Table 2. Absolute torque of the flexor and extensor muscles at the different elbow angles from the dominant and non-dominant sides of the control (top) and immobilized (bottom) groups (mean \pm SD).

\begin{tabular}{|c|c|c|c|c|c|c|c|c|}
\hline & \multicolumn{8}{|c|}{ Torque (Nm) } \\
\hline & \multicolumn{4}{|c|}{ Flexors } & \multicolumn{4}{|c|}{ Extensors } \\
\hline & \multicolumn{2}{|c|}{ Dominant } & \multicolumn{2}{|c|}{ Non-dominant } & \multicolumn{2}{|c|}{ Dominant } & \multicolumn{2}{|c|}{ Non-dominant } \\
\hline Angle $\left({ }^{\circ}\right)$ & Test 1 & Test 2 & Test 1 & Test 2 & Test 1 & Test 2 & Test 1 & Test 2 \\
\hline 180 & $36 \pm 15$ & $34 \pm 10$ & $38 \pm 12^{\mathrm{a}}$ & $35 \pm 09^{c}$ & $42 \pm 09$ & $42 \pm 09$ & $38 \pm 09$ & $38 \pm 10$ \\
\hline 150 & $51 \pm 16$ & $48 \pm 17$ & $48 \pm 15$ & $44 \pm 09$ & $49 \pm 13$ & $52 \pm 14$ & $54 \pm 11$ & $50 \pm 11$ \\
\hline 120 & $69 \pm 20$ & $67 \pm 19$ & $62 \pm 13$ & $61 \pm 11^{c}$ & $59 \pm 17$ & $64 \pm 18$ & $60 \pm 14$ & $57 \pm 11^{c}$ \\
\hline 90 & $76 \pm 16$ & $77 \pm 21$ & $79 \pm 17$ & $72 \pm 16$ & $62 \pm 15$ & $69 \pm 20$ & $60 \pm 13$ & $64 \pm 16^{c}$ \\
\hline 60 & $43 \pm 09^{\mathrm{a}}$ & $51 \pm 10^{a, c}$ & $46 \pm 11$ & $59 \pm 18$ & $44 \pm 12$ & $46 \pm 13$ & $40 \pm 11$ & $49 \pm 17^{c}$ \\
\hline Angle $\left({ }^{\circ}\right)$ & Pre & Post & Pre & Post & Pre & Post & Pre & Post \\
\hline 180 & $33 \pm 07$ & $32 \pm 04$ & $34 \pm 04^{a}$ & $27 \pm 06^{c}$ & $38 \pm 03$ & $41 \pm 05^{b}$ & $40 \pm 04^{a}$ & $33 \pm 08^{a, b}$ \\
\hline 150 & $44 \pm 7$ & $44 \pm 05$ & $48 \pm 07^{a}$ & $36 \pm 10^{a}$ & $46 \pm 06$ & $46 \pm 04$ & $50 \pm 08^{\mathrm{a}}$ & $40 \pm 08^{\mathrm{a}}$ \\
\hline 120 & $61 \pm 11$ & $62 \pm 09^{b}$ & $62 \pm 12^{\mathrm{a}}$ & $49 \pm 10^{\mathrm{a}, \mathrm{b}, \mathrm{c}}$ & $54 \pm 12$ & $56 \pm 07^{b}$ & $54 \pm 07$ & $47 \pm 07^{b, c}$ \\
\hline 90 & $75 \pm 15$ & $76 \pm 12^{b}$ & $74 \pm 10^{a}$ & $62 \pm 11^{\mathrm{a}, \mathrm{b}}$ & $59 \pm 16$ & $63 \pm 16^{b}$ & $60 \pm 10^{\mathrm{a}}$ & $49 \pm 06^{a, b, c}$ \\
\hline 60 & $55 \pm 11$ & $60 \pm 06^{b, c}$ & $57 \pm 11^{1, c}$ & $46 \pm 10^{a, b}$ & $46 \pm 15$ & $43 \pm 12^{b}$ & $41 \pm 07^{a}$ & $34 \pm 04^{a, b, c}$ \\
\hline
\end{tabular}

Letter $a=p<0.05$ between tests; letter $b=p<0.05$ between sides; letter $c=p<0.05$ between groups. Results from tests $1 / p$ re-immobilization and 2/post-immobilization were obtained with 14 days of interval. 
angles with immobilization $\left(180^{\circ}=18 \%, \mathrm{p}=0.026 ; 150^{\circ}=18 \%\right.$, $\left.\mathrm{p}=0.037 ; 90=17 \%, \mathrm{p}=0.007 ; 60^{\circ}=16 \%, \mathrm{p}=0,029\right)$, except for $120^{\circ}$. There was a reduction in the post-immobilization absolute torque of the non-dominant (immobilized) side compared to dominant side at the joint angles of $180^{\circ}(\mathrm{p}=0.031), 120^{\circ}$ $(\mathrm{p}=0.006), 90^{\circ}(\mathrm{p}=0.026)$ and $60^{\circ}(\mathrm{p}=0.048)$. The inter-group comparison revealed a decrease in absolute extensor torque of the non-dominant (immobilized) side of the immobilization group at the joint angles of $120^{\circ}(p=0.022), 90^{\circ}(p=0.013)$ and $60^{\circ}(\mathrm{p}=0.011)$ compared to the control group after immobilization (Table 2).

No changes were observed in the normalized torque between sides (dominant vs. non-dominant) and between tests (1 and 2) in the control group. Also, no differences were observed between pre- and post-immobilization evaluations or between sides (control vs. immobilized) after treatment in the immobilization group (Table 3). As the behavior of the normalized torque was similar between the dominant and non-dominant sides of the control group and the dominant (non-immobilized) side of the immobilization group, results from the dominant (non-immobilized) side were considered as the control of the immobilization group.

\section{EMG data}

No differences were observed in the absolute (Tables 4 and 5) and normalized (Tables 6 and 7) RMS values between tests, between sides or between groups in any of the studied muscles (i.e. two portions or heads of biceps brachii, triceps brachii and brachioradialis). Normalized RMS values remained about constant with increasing muscle length both for the elbow flexors and extensors (Tables 6 and 7).

\section{Discussion : :}

Muscle mass can be indirectly measured by a segment's perimeter. Although limited and indirect, it is used in the clinical set-up to determine inter-limb differences and has been used to estimate muscle mass ${ }^{1,224}$. The arm perimeters were similar between the pre- and post-immobilization evaluation, suggesting that the perimeter is not a good tool to estimate muscle mass, that the reduction in muscle mass was offset by an increase in subcutaneous fat tissue, or that muscle mass does not change after fourteen days of immobilization in healthy subjects. The methodology used, however, does not allow determining which of the above possibilities occurred.

Kitahara et al. ${ }^{24}$ did not find differences in arm perimeter or in the magnetic resonance images after 21 days of elbow immobilization in healthy subjects. McDougall et al. ${ }^{25}$, however, found a $5 \%$ reduction in arm perimeter after five weeks of elbow immobilization in healthy subjects. This difference may be partly due to the different immobilization time of the studies or due to the site of the perimeter measurements. Also, as immobilization was applied to healthy subjects with no pain and/or injury, subjects were able to freely move their shoulder and hand in ADLs, maintaining a regular use of the limb and preventing loss of muscle mass.

As expected, no changes were observed either in the absolute torque and RMS values of elbow flexors and extensors in the control group between tests one and two except for the absolute torque at $60^{\circ}$ (Table 2). The absence of differences in absolute torque between groups during test 1 on both sides (dominant and non-dominant) is evidence that the two groups had similar torque production capability before treatment. After immobilization, there was a general reduction in the

Table 3. Normalized torques of the flexor and extensor muscles obtained at the different elbow angles from the dominant and non-dominant sides of the control (top) and immobilization (bottom) groups (mean ${ }_{ \pm} S D ;{ }^{*}=p<0.05$ between the tests). Results from tests $1 /$ pre-immobilization and 2/post-immobilization were obtained with 14 days of interval. Torques were normalized to the torque obtained at the elbow angle of $90^{\circ}$. There was no difference in the relative torque between tests in flexors and extensors in both groups.

\begin{tabular}{lcccccccc}
\hline & \multicolumn{3}{c}{ Flexors } & \multicolumn{2}{c}{ Normalized Torque (\%) } & \multicolumn{2}{c}{ Extensors } \\
& \multicolumn{2}{c}{ Dominant } & \multicolumn{2}{c}{ Non-dominant } & \multicolumn{2}{c}{ Dominant } & \multicolumn{2}{c}{ Non-dominant } \\
Angle $\left(^{\circ}\right)$ & Test 1 & Test 2 & Test 1 & Test 2 & Test 1 & Test 2 & Test 1 & Test 2 \\
\hline 180 & $47 \pm 16$ & $45 \pm 13$ & $57 \pm 18$ & $49 \pm 11$ & $68 \pm 9$ & $63 \pm 10$ & $65 \pm 19$ & $61 \pm 17$ \\
\hline 150 & $67 \pm 14$ & $62 \pm 12$ & $71 \pm 20$ & $62 \pm 10$ & $80 \pm 10$ & $76 \pm 9$ & $91 \pm 17$ & $79 \pm 18$ \\
\hline 120 & $90 \pm 13$ & $86 \pm 11$ & $92 \pm 17$ & $86 \pm 16$ & $93 \pm 10$ & $93 \pm 7$ & $100 \pm 17$ & $91 \pm 13$ \\
\hline 60 & $59 \pm 15$ & $68 \pm 18$ & $68 \pm 11$ & $78 \pm 18$ & $71 \pm 8$ & $69 \pm 10$ & $68 \pm 17$ & $76 \pm 11$ \\
\hline Angle $\left(^{\circ}\right)$ & Pre & Post & Pre & Post & Pre & Post & Pre & Post \\
\hline 180 & $46 \pm 11$ & $43 \pm 08$ & $47 \pm 08$ & $45 \pm 06$ & $69 \pm 22$ & $70 \pm 24$ & $69 \pm 14$ & $67 \pm 14$ \\
\hline 150 & $61 \pm 14$ & $58 \pm 09$ & $66 \pm 09$ & $58 \pm 08$ & $84 \pm 23$ & $78 \pm 23$ & $84 \pm 16$ & $81 \pm 11$ \\
\hline 120 & $82 \pm 11$ & $81 \pm 03$ & $85 \pm 11$ & $79 \pm 05$ & $95 \pm 13$ & $93 \pm 21$ & $90 \pm 10$ & $95 \pm 09$ \\
\hline 60 & $74 \pm 06$ & $83 \pm 09$ & $78 \pm 15$ & $74 \pm 05$ & $77 \pm 08$ & $69 \pm 10$ & $69 \pm 08$ & $69 \pm 06$ \\
\hline
\end{tabular}


Table 4. Absolute RMS values (mean \pm SD) from all muscles and joint angles of the dominant (non-immobilized) side of the control and immobilized groups for tests 1 and 2, and pre- and post-immobilization, respectively.

\begin{tabular}{|c|c|c|c|c|}
\hline \multirow{3}{*}{$\begin{array}{l}\text { Group } \\
\text { Muscles Angles }\end{array}$} & \multicolumn{4}{|c|}{ RMS Values (mVolts) } \\
\hline & \multicolumn{2}{|c|}{ Control } & \multicolumn{2}{|c|}{ Immobilization } \\
\hline & Test 1 & Test 2 & Pre & Post \\
\hline BC 180 & $0.738 \pm 0.290$ & $0.881 \pm 0.391$ & $0.629 \pm 0.190$ & $0.540 \pm 0.168$ \\
\hline BC 150 & $0.696 \pm 0.272$ & $1.146 \pm 1.076$ & $0.740 \pm 0.216$ & $0.626 \pm 0.257$ \\
\hline BC 120 & $0.606 \pm 0.289$ & $0.938 \pm 0.297$ & $0.731 \pm 0.242$ & $0.686 \pm 0.301$ \\
\hline BC 90 & $0.785 \pm 0.342$ & $1.010 \pm 0.391$ & $0.872 \pm 0.499$ & $0.900 \pm 0.036$ \\
\hline BC 60 & $0.750 \pm 0.424$ & $0.938 \pm 0.556$ & $0.754 \pm 0.412$ & $0.905 \pm 0.447$ \\
\hline BL 180 & $0.483 \pm 0.212$ & $0.606 \pm 0.300$ & $0.541 \pm 0.213$ & $0.508 \pm 0.257$ \\
\hline BL 150 & $0.477 \pm 0.236$ & $0.887 \pm 0.673$ & $0.658 \pm 0.281$ & $0.604 \pm 0.366$ \\
\hline BL 120 & $0.461 \pm 0.243$ & $0.825 \pm 0.809$ & $0.595 \pm 0.338$ & $0.629 \pm 0.409$ \\
\hline BL 90 & $0.491 \pm 0.190$ & $0.590 \pm 0.175$ & $0.610 \pm 0.449$ & $0.772 \pm 0.043$ \\
\hline BL 60 & $0.503 \pm 0.302$ & $0.669 \pm 0.359$ & $0.574 \pm 0.381$ & $0.674 \pm 0.356$ \\
\hline BR 180 & $0.553 \pm 0.268$ & $0.625 \pm 0.307$ & $0.461 \pm 0.133$ & $0.405 \pm 0.086$ \\
\hline BR 150 & $0.526 \pm 0.234$ & $0.767 \pm 0.539$ & $0.533 \pm 0.122$ & $0.472 \pm 0.155$ \\
\hline BR 120 & $0.584 \pm 0.237$ & $0.705 \pm 0.316$ & $0.591 \pm 0.203$ & $0.480 \pm 0.084$ \\
\hline BR 90 & $0.754 \pm 0.343$ & $0.812 \pm 0.301$ & $0.622 \pm 0.314$ & $0.587 \pm 0.129$ \\
\hline BR 60 & $0.751 \pm 0.330$ & $0.910 \pm 0.397$ & $0.636 \pm 0.372$ & $0.618 \pm 0.208$ \\
\hline TC 180 & $0.645 \pm 0.493$ & $0.685 \pm 0.313$ & $0.654 \pm 0.027$ & $0.583 \pm 0.155$ \\
\hline TC 150 & $0.728 \pm 0.497$ & $0.820 \pm 0.416$ & $0.765 \pm 0.366$ & $0.615 \pm 0.162$ \\
\hline TC 120 & $0.684 \pm 0.421$ & $0.942 \pm 0.681$ & $0.743 \pm 0.276$ & $0.747 \pm 0.244$ \\
\hline TC 90 & $0.891 \pm 0.570$ & $0.863 \pm 0.422$ & $0.874 \pm 0.033$ & $0.878 \pm 0.348$ \\
\hline TC 60 & $0.651 \pm 0.425$ & $0.665 \pm 0.329$ & $0.710 \pm 0.219$ & $0.658 \pm 0.242$ \\
\hline TL 180 & $0.351 \pm 0.118$ & $0.508 \pm 0.231$ & $0.380 \pm 0.151$ & $0.416 \pm 0.104$ \\
\hline TL 150 & $0.366 \pm 0.111$ & $0.606 \pm 0.284$ & $0.383 \pm 0.145$ & $0.328 \pm 0.131$ \\
\hline TL 120 & $0.342 \pm 0.120$ & $0.483 \pm 0.180$ & $0.341 \pm 0.117$ & $0.331 \pm 0.122$ \\
\hline TL 90 & $0.352 \pm 0.120$ & $0.457 \pm 0.218$ & $0.356 \pm 0.074$ & $0.343 \pm 0.113$ \\
\hline TL 60 & $0.280 \pm 0.116$ & $0.350 \pm 0.157$ & $0.270 \pm 0.096$ & $0.279 \pm 0.011$ \\
\hline
\end{tabular}

BC=biceps brachii short head; BL=biceps brachii long head; BR=brachioradialis; TC=triceps brachii short head; TL=triceps brachii long head. Pre=before immobilization; post=after immobilization.

maximal absolute torque at all joint angles (Table 2), suggesting a general reduction in muscle strength production of elbow flexor and extensor muscles. Length-dependent adaptation is related to the length at which a muscle is immobilized ${ }^{18}$, but as immobilization was applied at intermediate muscle lengths, no changes were expected in the behavior of torque as a function of elbow angle. This is due to the fact that the number of sarcomeres in series, which could affect this relationship, has been shown to change only when muscles were immobilized at extremely short or long lengths ${ }^{15}$.

The results of Table 3 are in accordance with the idea that immobilization at an intermediate joint angle does not affect the number of sarcomeres in series, as there was no change in the normalized torque of flexors and extensors at all angles. Similarly, Geboers et al. ${ }^{26}$ did not find any changes in torque production at specific joint angles. According to the authors, tissue changes due to immobilization seem to have equally affected torque production at all joint angles. The intermediate angle for immobilization (i.e. $90^{\circ}$ ) was chosen for ethical reasons. Although the effects of immobilization are reversible, a substantial amount of time is needed to regain a normal range of motion, which would disturb the subjects' ADLs. Moreover, it would be very difficult to find subjects willing to have their elbows immobilized at extreme joint positions (i.e. totally flexed or extended), as they would need special care to be able to perform their ADLs. However, the methodology chosen is closely related to clinical situations, as elbow immobilization after injuries use a similar position.

Antigravity muscles are more prone to a reduction in structure and function than non-gravity muscles due to the greater reduction in their use during immobilization. Hortobágyi et al. ${ }^{27}$, for example, found a $47 \%$ reduction in knee extensor maximal strength after three weeks of knee immobilization. This considerable reduction in strength production is probably due to the systematic use of lower limb muscles for weight bearing, locomotion and most ADLs, carrying a heavier load compared to upper limb muscles. In this sense, Boer et al. ${ }^{28}$ observed a reduction in muscle thickness, fascicle length and pennation angle of the medial gastrocnemius and vastus lateralis (antigravity) muscles 
Table 5. Absolute RMS values (mean $\pm S D$ ) from all muscles and joint angles of the non-dominant side of the control and immobilization groups for tests 1 and 2, and pre- and post-immobilization, respectively.

\begin{tabular}{|c|c|c|c|c|}
\hline \multirow{3}{*}{$\begin{array}{l}\text { Group } \\
\text { Muscles Angles }\end{array}$} & \multicolumn{4}{|c|}{ RMS Values (mVolts) } \\
\hline & \multicolumn{2}{|c|}{ Control } & \multicolumn{2}{|c|}{ Immobilization } \\
\hline & Test 1 & Test 2 & Pre & Post \\
\hline BC 180 & $0.602 \pm 0.245$ & $0.656 \pm 0.291$ & $0.726 \pm 0.312$ & $0.596 \pm 156$ \\
\hline BC 150 & $0.607 \pm 0.292$ & $0.716 \pm 0.407$ & $0.742 \pm 0.33$ & $0.514 \pm 0.155$ \\
\hline BC 120 & $0.582 \pm 0.221$ & $0.644 \pm 0.272$ & $0.652 \pm 0.299$ & $0.537 \pm 0.3$ \\
\hline BC 90 & $0.802 \pm 0.330$ & $0.794 \pm 0.299$ & $0.793 \pm 0.288$ & $0.673 \pm 0.354$ \\
\hline BC 60 & $0.705 \pm 0.312$ & $0.853 \pm 0.394$ & $0.687 \pm 0.169$ & $0.655 \pm 0.344$ \\
\hline BL 180 & $0.474 \pm 0.317$ & $0.527 \pm 0.311$ & $0.515 \pm 0.143$ & $0.487 \pm 0.162$ \\
\hline BL 150 & $0.554 \pm 0.329$ & $0.562 \pm 0.239$ & $0.615 \pm 0.342$ & $0.405 \pm 0.155$ \\
\hline BL 120 & $0.558 \pm 0.311$ & $0.524 \pm 0.305$ & $0.483 \pm 0.219$ & $0.364 \pm 0.141$ \\
\hline BL 90 & $0.675 \pm 0.381$ & $0.495 \pm 0.208$ & $0.579 \pm 0.22$ & $0.370 \pm 0.195$ \\
\hline BL 60 & $0.649 \pm 0.344$ & $0.625 \pm 0.286$ & $0.537 \pm 0.2$ & $0.396 \pm 0.218$ \\
\hline BR 180 & $0.513 \pm 0.279$ & $0.593 \pm 0.239$ & $0.534 \pm 0.195$ & $0.566 \pm 0.309$ \\
\hline BR 150 & $0.552 \pm 0.263$ & $0.599 \pm 0.224$ & $0.519 \pm 0.163$ & $0.442 \pm 0.157$ \\
\hline BR 120 & $0.537 \pm 0.210$ & $0.580 \pm 0.214$ & $0.520 \pm 0.195$ & $0.396 \pm 0.141$ \\
\hline BR 90 & $0.610 \pm 0.272$ & $0.656 \pm 0.222$ & $0.640 \pm 0.156$ & $0.543 \pm 0.117$ \\
\hline BR 60 & $0.681 \pm 0.323$ & $0.769 \pm 0.278$ & $0.549 \pm 0.15$ & $0.465 \pm 0.0091$ \\
\hline TC 180 & $0.785 \pm 0.547$ & $0.658 \pm 0.358$ & $0.599 \pm 0.224$ & $0.434 \pm 0.133$ \\
\hline TC 150 & $0.814 \pm 0.540$ & $0.672 \pm 0.341$ & $0.633 \pm 0.265$ & $0.655 \pm 0.439$ \\
\hline TC 120 & $0.874 \pm 0.551$ & $0.736 \pm 0.335$ & $0.839 \pm 0.448$ & $0.605 \pm 0.211$ \\
\hline TC 90 & $0.902 \pm 0.500$ & $0.761 \pm 0.395$ & $0.795 \pm 0.352$ & $0.707 \pm 0.233$ \\
\hline TC 60 & $0.637 \pm 0.449$ & $0.629 \pm 0.386$ & $0.717 \pm 0.256$ & $0.541 \pm 0.134$ \\
\hline TL 180 & $0.394 \pm 0.179$ & $0.396 \pm 0.135$ & $0.327 \pm 0.136$ & $0.278 \pm 0.124$ \\
\hline TL 150 & $0.404 \pm 0.165$ & $0.394 \pm 0.108$ & $0.288 \pm 0.122$ & $0.301 \pm 0.0090$ \\
\hline TL 120 & $0.384 \pm 0.187$ & $0.378 \pm 0.090$ & $0.314 \pm 0.143$ & $0.260 \pm 0.124$ \\
\hline TL 90 & $0.421 \pm 0.210$ & $0.377 \pm 0.111$ & $0.350 \pm 0.0091$ & $0.314 \pm 0.122$ \\
\hline TL 60 & $0.287 \pm 0.145$ & $0.268 \pm 0.055$ & $0.258 \pm 0.080$ & $0.245 \pm 0.108$ \\
\hline
\end{tabular}

$\mathrm{BC}=$ biceps brachii short head; BL=biceps brachii long head; BR=brachioradialis; TC=triceps brachii short head; TL=triceps brachii long head. Pre=before immobilization; post=after immobilization.

and no differences in the tibialis anterior and biceps brachii muscles (non-antigravity) after five weeks of bed rest. This is evidence that different muscles have different responses to reduced muscle use. However, the authors emphasize that interpretation should be taken with caution as bed rest studies may produce chronic positions and compensatory activities that may affect the observed results.

According to Yue et al..$^{29}$, weight bearing muscles undergo greater hypotrophy when their normal usage levels are reduced compared to upper limb muscles ${ }^{30}$. Upper limb immobilization studies show a variation in relative strength reduction between $18 \%$ and $55 \%^{24,25,31}$. The $16 \%$ reduction in muscle torque of the present study is close to the lower values; however, this great variation emphasizes the fact that the immobilization methodology, which varied amongst studies, is an important and determinant factor for strength reduction. Although flexor muscles were expected to show higher structural and functional changes after immobilization compared to elbow extensors (due to the higher overload during elbow flexion compared to extension in $\mathrm{ADLs}$ ), the $16 \%$ reduction in the absolute torque of flexors and extensors at optimal length $\left(90^{\circ}\right)$ did not show this preferential adaptation.

Strength reduction usually occurs in the first days of immobilization at a rate of $1 \%$ to $6 \%$ per day ${ }^{31,32}$. Our results are within this range as the immobilization group subjects lost about $1.14 \%$ in torque per day of immobilization. As the relative loss in strength is greater than the relative loss in muscle mass ${ }^{8}$, this strength decrease after immobilization cannot be due solely to a reduction in muscle mass or to muscle hypotrophy. Changes in the neural drive have also been indicated as a factor responsible for strength reduction ${ }^{8,28,30,32,33}$, however, the fact that the absolute EMG signals (Tables 4 and 5) did not change with immobilization seems to go against this idea, although the reduced number of subjects (7) in the immobilization group may have affected our results. Despite the fact that almost all RMS values of all muscles in the non-dominant (immobilized) side are smaller after immobilization compared to the pre-immobilization evaluation (Table 5), this reduced sample size may have increased the variance in the absolute RMS values affecting the statistical results (type 2 error). 
Table 6. Normalized RMS values (mean $\pm S D$ ) from all muscles and joint angles of the dominant (non-immobilized) side of the control and immobilization groups for tests 1 and 2, and pre- and postimmobilization, respectively.

\begin{tabular}{|c|c|c|c|c|}
\hline \multirow{3}{*}{$\begin{array}{l}\text { Group } \\
\text { Muscles Angles }\end{array}$} & \multicolumn{4}{|c|}{ RMS (\%) } \\
\hline & \multicolumn{2}{|c|}{ Control } & \multicolumn{2}{|c|}{ Immobilization } \\
\hline & Test 1 & Test 2 & Pre & Post \\
\hline BC 180 & $101 \pm 27$ & $103 \pm 59$ & $85 \pm 33$ & $64 \pm 15$ \\
\hline BC 150 & $98 \pm 34$ & $91 \pm 56$ & $102 \pm 42$ & $73 \pm 17$ \\
\hline BC 120 & $82 \pm 34$ & $105 \pm 53$ & $99 \pm 39$ & $79 \pm 16$ \\
\hline $\mathrm{BC} 60$ & $94 \pm 51$ & $99 \pm 49$ & $94 \pm 33$ & $104 \pm 37$ \\
\hline BL 180 & $104 \pm 36$ & $106 \pm 48$ & $118 \pm 66$ & $68 \pm 16$ \\
\hline BL 150 & $98 \pm 37$ & $126 \pm 67$ & $139 \pm 69$ & $78 \pm 21$ \\
\hline BL 120 & $95 \pm 32$ & $100 \pm 35$ & $113 \pm 44$ & $82 \pm 25$ \\
\hline BL 60 & $96 \pm 35$ & $116 \pm 56$ & $104 \pm 51$ & $91 \pm 35$ \\
\hline BR 180 & $78 \pm 20$ & $77 \pm 20$ & $82 \pm 30$ & $70 \pm 16$ \\
\hline BR 150 & $75 \pm 23$ & $80 \pm 19$ & $96 \pm 31$ & $81 \pm 25$ \\
\hline BR 120 & $82 \pm 18$ & $83 \pm 13$ & $102 \pm 25$ & $84 \pm 19$ \\
\hline BR 60 & $97 \pm 28$ & $114 \pm 33$ & $101 \pm 20$ & $104 \pm 14$ \\
\hline TC 180 & $74 \pm 29$ & $84 \pm 28$ & $77 \pm 23$ & $75 \pm 31$ \\
\hline TC 150 & $85 \pm 27$ & $98 \pm 32$ & $87 \pm 18$ & $74 \pm 19$ \\
\hline TC 120 & $81 \pm 21$ & $107 \pm 46$ & $86 \pm 15$ & $90 \pm 25$ \\
\hline TC 60 & $77 \pm 46$ & $79 \pm 24$ & $85 \pm 16$ & $76 \pm 12$ \\
\hline TL 180 & $104 \pm 27$ & $117 \pm 33$ & $103 \pm 26$ & $131 \pm 59$ \\
\hline TL 150 & $108 \pm 25$ & $118 \pm 28$ & $104 \pm 26$ & $95 \pm 18$ \\
\hline TL 120 & $98 \pm 20$ & $109 \pm 23$ & $93 \pm 20$ & $101 \pm 44$ \\
\hline TL 60 & $78 \pm 16$ & $81 \pm 31$ & $74 \pm 14$ & $93 \pm 69$ \\
\hline
\end{tabular}

$\mathrm{BC}=$ biceps brachii short head; $\mathrm{BL}=$ biceps brachii long head; $\mathrm{BR}=$ brachioradialis; TC=triceps brachii short head; TL=triceps brachii long head. Pre=before immobilization; post=after immobilization.

Despite this lack of statistical difference, these results suggest that the analysis of raw or absolute EMG signals may reveal differences in muscle function that cannot be observed when the data is normalized.

Similar to what happens during the early stages of strength training (where neural factors are responsible to $80 \%$ of strength increases, as shown by increases in the EMG signals) ${ }^{6}$, a reduction in the RMS values of the EMG signals was expected to occur at all joint angles and muscles between the pre- and postimmobilization evaluations. Furthermore, the greatest changes in muscle activity occur during the first few days of reduced use, and the ratio of loss diminishes progressively ${ }^{3,8}$. The fact that we did not find any changes in the EMG signals after immobilization was unexpected and surprising. Perhaps in addition to the above mentioned sample size, the lack of injury or pain may have prevented these changes in muscle activation, as pain may inhibit or change the firing threshold of motor units ${ }^{33,34}$. We were unable to compare our results with previous studies due to the different methodology (e.g. different time frames, different muscles) and different models of reduced use.

Although there is evidence of changes in the neural drive with immobilization', the mechanism responsible for the
Table 7. Normalized RMS values (mean $\pm S D$ ) from all muscles and joint angles of the non-dominant side of the control and immobilization groups for tests 1 and 2, and pre- and post-immobilization, respectively.

\begin{tabular}{|c|c|c|c|c|}
\hline \multirow{3}{*}{$\begin{array}{l}\text { Group } \\
\text { Muscle Angle }\end{array}$} & \multicolumn{4}{|c|}{ RMS (\%) } \\
\hline & \multicolumn{2}{|c|}{ Control } & \multicolumn{2}{|c|}{ Immobilization } \\
\hline & Test 1 & Test 2 & Pre & Post \\
\hline BC 180 & $86 \pm 37$ & $91 \pm 67$ & $91 \pm 34$ & $82 \pm 34$ \\
\hline BC 150 & $85 \pm 39$ & $100 \pm 76$ & $97 \pm 33$ & $82 \pm 31$ \\
\hline BC 120 & $83 \pm 35$ & $89 \pm 57$ & $85 \pm 29$ & $87 \pm 35$ \\
\hline BC 60 & $94 \pm 31$ & $113 \pm 53$ & $85 \pm 12$ & $98 \pm 17$ \\
\hline BL 180 & $79 \pm 37$ & $109 \pm 61$ & $92 \pm 16$ & $116 \pm 49$ \\
\hline BL 150 & $90 \pm 34$ & $120 \pm 68$ & $107 \pm 37$ & $126 \pm 52$ \\
\hline BL 120 & $95 \pm 33$ & $109 \pm 46$ & $83 \pm 25$ & $109 \pm 47$ \\
\hline $\mathrm{BL} 60$ & $113 \pm 54$ & $132 \pm 64$ & $94 \pm 18$ & $109 \pm 25$ \\
\hline BR 180 & $80 \pm 18$ & $90 \pm 24$ & $83 \pm 20$ & $85 \pm 27$ \\
\hline BR 150 & $89 \pm 12$ & $90 \pm 24$ & $80 \pm 12$ & $83 \pm 29$ \\
\hline BR 120 & $90 \pm 11$ & $86 \pm 14$ & $79 \pm 14$ & $72 \pm 12$ \\
\hline BR 60 & $110 \pm 11$ & $120 \pm 21$ & $87 \pm 20$ & $87 \pm 10$ \\
\hline TC 180 & $83 \pm 27$ & $82 \pm 20$ & $80 \pm 21$ & $66 \pm 27$ \\
\hline TC 150 & $87 \pm 22$ & $89 \pm 21$ & $81 \pm 22$ & $74 \pm 20$ \\
\hline TC 120 & $94 \pm 21$ & $100 \pm 21$ & $105 \pm 40$ & $87 \pm 20$ \\
\hline TC 60 & $67 \pm 17$ & $77 \pm 31$ & $95 \pm 13$ & $83 \pm 32$ \\
\hline TL 180 & $104 \pm 33$ & $10 \pm 27$ & $93 \pm 26$ & $90 \pm 26$ \\
\hline TL 150 & $110 \pm 43$ & $105 \pm 21$ & $82 \pm 30$ & $87 \pm 14$ \\
\hline TL 120 & $96 \pm 20$ & $98 \pm 16$ & $89 \pm 30$ & $83 \pm 19$ \\
\hline TL 60 & $70 \pm 14$ & $68 \pm 12$ & $75 \pm 21$ & $78 \pm 15$ \\
\hline
\end{tabular}

$\mathrm{BC}=$ biceps brachii short head; $\mathrm{BL}=$ biceps brachii long head; $\mathrm{BR}=$ brachioradialis $\mathrm{TC}=$ triceps brachii short head; $\mathrm{TL}=t$ riceps brachii long head. Pre=before immobilization; post=after immobilization.

reduction in muscle strength seems to have other possible components. Berg and Tesch ${ }^{9}$ did not find differences in the EMG signals after ten days of lower limb suspension. They attributed their results to changes in the ability of calcium release from the sarcoplasmic reticulum or to a reduction in the number of cross-bridges, or to some change in the contractile apparatus that might be compatible with the absence of changes in the EMG signals. An attempt to explain this reduction in muscle strength was made by Pathare et al. ${ }^{35}$, who found increased levels of inorganic phosphate in the muscle after immobilization, which would inhibit muscle contraction by preventing the connection of the myosin heads with the actin filaments. However, they do not explain how this increase in muscle inorganic phosphate is responsible for the inhibition of the contractile apparatus.

In summary, there was a general reduction in torque production of elbow flexors and extensors after 14 days of immobilization in healthy subjects. No changes were observed in the EMG signals, and no differences were observed in arm perimeter. It appears, therefore, that torque reduction after immobilization is related to an intrinsic muscle factor that is not easily determined during in vivo muscle preparations in healthy subjects. 
New studies should determine whether changes in neural factors are predominantly associated with immobilization due to injury. Determining the exact mechanisms of muscle strength should be very important when designing rehabilitation programs for the musculoskeletal system.

\section{Acknowledgements : $:$.}

The authors would like to thank Conselho Nacional de Desenvolvimento Científico e Tecnológico (CNPq) for their financial support.

\section{References $: \because$.}

1. Chor H, Dolkart RE. A study of "simple disuse atrophy" in the monkey. Am J Physiol. 1936;117:626-30.

2. Fischer E, Ramsey VW. Changes in protein content and in some physicochemical properties of the protein during muscular atrophies of various types. Am J Physiol. 1946;145:571-82.

3. Appell HJ. Muscular atrophy following immobilization: a review. Sports Med. 1990;10(1):42-58.

4. Fração VB, Vaz MA. Influência da adaptação funcional na capacidade de produção de força no músculo esquelético. Revista Perfil. 2000;4: 103-10.

5. Edgerton VR, Roy RR, Allen DL, Monti RJ. Adaptations in skeletal muscle disuse or decreased-use atrophy. Am J Phys Med Rehabil. 2002;8 Suppl 11:S127-47.

6. Moritani T, deVries HA. Neural factors versus hypertrophy in the time course of muscle strength gain. Am J Phys Med. 1979;58(3): $115-30$.

7. Kitai TA, Sale DG. Specifity of joint angle in isometric training. Eur J Appl Physiol. 1989;58:744-8.

8. Seki K, Taniguchi $Y$, Narusawa M. Alterations in contractile properties of human skeletal muscle induced by joint immobilization. J Physiol. 2001;530(3):521-32.

9. Berg HE, Tesch PA. Changes in muscle function in response to 10 days of lower limb unloading in humans. Acta Physiol Scand. 1996;157(1): 63-70.

10. Lambertz D, Goubel F, Kaspranski R, Pérot C. Influence of long-term spaceflight on neuromechanical properties of muscles in humans. J Appl Physiol. 2003;94(2):490-8.

11. Andersen JL, Gruschy-Knudsen T, Sandri C, Larsson L, Schiaffino S. Bed rest increases the amount of mismatched fibers in human skeletal muscle. J Appl Physiol. 1999;86(2):455-60.

12. Fournier M, Roy RR, Perham H, Simard CP, Edgerton VR. Is limb immobilization a model of muscle disuse? Exp Neurol. 1983;80(1):147-56.

13. Lieber RL, Fridén JO, Hargens AR, Danzig LA, Gershuni DH. Differential response of the dog quadriceps muscle to external skeletal fixation of the knee. Muscle Nerve. 1988;11(3):193-201.

14. Lieber RL. Skeletal muscle structure and function: implications for rehabilitation and sports medicine. USA: Williams \& Wilkins; 1992.
15. Fischbach GD, Robbins N. Changes in contractile properties of disused soleus muscles. J Physiol. 1969;201(2):305-20.

16. Maier A, Crockett JL, Simpson DR, Saubert CW IV, Edgerton VR, Properties of immobilized guinea pig hindlimb muscles. Am J Physiol. 1976;231(5 Pt 1):1520-6.

17. Witzmann FA, Kim DH, Fitts RH. Hindlimb immobilization: lengthtension and contractile properties of skeletal muscle. J Appl Physiol. 1982;53(2):335-45.

18. Tabary JC, Tabary C, Tardieu C, Tardieu G, Goldspink G. Physiological and structural changes in the cat's soleus muscle due to immobilization at different lengths by plaster casts. J Physiol. 1972;224(1):231-44.

19. Petit J, Gioux M. Properties of motor units after immobilization of cat peroneus longus muscle. J Appl Physiol. 1993;74(3):1131-9.

20. Berg HE, Larsson L, Tesch PA. Lower limb skeletal muscle function after 6 wk of bed rest. J Appl Physiol. 1997;82(1):182-8.

21. Nigg B, Herzog W. Biomechanics of the musculo-skeletal system. Toronto: John Wiley \& Sons; 1994.

22. Mathur S, Eng JJ, MacIntyre DL. Reliability of surface EMG during sustained contractions of the quadriceps. J Electromyogr Kinesiol. 2005;15(1):102-10.

23. Vaz MA, Zhang YT, Herzog W, Guimarães ACS, Maclntosh BR. The behavior of rectus femoris and vastus lateralis during fatigue and recovery: an electromyographic and vibromyographic study. Electromyogr Clin Neurophysiol. 1996;36(4):221-30.

24. Kitahara A, Hamaoka T, Murase N, Homma T, Kurosawa Y, Ueda C, et al. Deterioration of muscle function after 21-day forearm immobilization. Med Sci Sports Exerc. 2003;35(10):1697-702.

25. MacDougall JD, Ward GR, Sale DG, Sutton JR. Biochemical adaptation of human skeletal muscle to heavy resistance training and immobilization. J Appl Physiol. 1977;43(4):700-3.

26. Geboers JF, van Tujil JH, Seelen HA, Drost MR. Effect of immobilization on ankle dorsiflexion strength. Scand J Rehab Med. 2000;32(2):66-71.

27. Hortobágyi T, Dempsey L, Fraser D, Zheng D, Hamilton G, Lambert J, et al. Changes in muscle strength, muscle fiber size and myofibrillar gene expression after immobilization and retraining in humans. J Physiol. 2000;524(1):293-304.

28. de Boer MD, Seynnes OR, di Prampero PE, Pisot R, Mekjavic IB, Biolo G, et al. Effect of 5 weeks horizontal bed rest on human muscle thickness and 
architecture of weight bearing and non-weight bearing muscles. Eur J Appl Physiol. 2008;104(2):401-7.

29. Yue GH, Bilodeau M, Hardy PA, Enoka RM. Task-dependent effect of limb immobilization on the fatigability of the flexor muscles in humans. Exp Physiol. 1997;82(3):567-92.

30. Fuglevand AJ, Bilodeau M, Enoka RM. Short-term immobilization has a minimal effect on the strength and fatigability of a human hand muscle. J Appl Physiol. 1995;78(3):847-55.

31. Semmler JG, Kutzscher DV, Enoka RM. Limb immobilization alters muscle activation patterns during a fatiguing isometric contraction. Muscle Nerve. 2000;23(9):1381-92.
32. Müller EA. Influence of training and of inactivity on muscle strength. Arch Phys Med Rehabil. 1970;51(8):449-62.

33. Hather BM, Adams GR, Tesch PA, Dudley GA. Skeletal muscle responses to lower limb suspension in humans. J Appl Physiol. 1992;72(4):1493-8.

34. Häggmark T, Jansson E, Erikson E. Fiber type area and metabolic potential of the thigh muscle in man after surgery and immobilization. Int J Sports Med. 1981;2(1):12-7.

35. Pathare NC, Stevens JE, Walter GA, Shah P, Jayaraman A, Tillman SM, et al. Deficit in human muscle strength with cast immobilization: contribution of inorganic phosphate. Eur J Appl Physiol. 2006;98(1):71-8. 